\title{
Os Papéis da CIÊNCIA Dos \\ MATERIAIS E DA ENGENHARIA PARA \\ UMA SOCIEDADE SUSTENTÁvEL
}

\author{
SOOKAP HAHN \\ (Unipersidade de Stanford, Palo Alto, EUA)
}

\begin{abstract}
Tossa civilização entrou em uma nova era de materiais. Como está 1 fartamente documentado em vários relatórios governamentais e acadêmicos, as sociedades avançadas em todo o mundo rapidamente adquirem habilidades sem precedentes no sentido de criar materiais projetados para satisfazer necessidades humanas. Em todo país, a qualidade de vida e segurança econômica e militar dependem cada vez mais da capacidade de sintetizar e processar materiais, de descobrir novos e de integrá-los em tecnologias de manufatura economicamente eficientes e ecologicamente seguras. Na verdade, sem os novos materiais e sua produção eficiente, não existiria o nosso mundo de equipamentos modernos, máquinas, computadores, automóveis, aeronaves, aparelhos de comunicação e produtos estruturais. Cientistas e engenheiros de materiais continuarão a estar na dianteira dessas e de outras áreas de ciência e engenharia a serviço da sociedade, à medida qúe conquistem novos níveis de entendimento e controle sobre os blocos básicos que compóem os materiais: átomos, moléculas, cristais e arranjos não-cristalinos.
\end{abstract}

Nesta apresentação, descreverei alguns requisitos da pesquisa e desenvolvimento de materiais para cinco áreas de interesse nacionais, cujo objetivo é atingir uma sociedade sustentável com alta qualidade de vida: informação/comunicaçáo, transportes, energia, saúde e desenvolvimento.

\section{Informação/comunicação}

Avanços na eletrônica e na fotônica estão mudando a forma como vivemöos e trabalhamos e a maneira como interagimos, seja entre nós, seja com ferramentas e máquinas ou com nosso meio-ambiente.

Ós avanços dependem de ciência e engenharia de materiais, particularmente de síntese e processamento e sua relaçáo com o desèmpenho? Os materiais mais críticos relacionados a processamento de informação 
e hardware de armazenagem são os materiais semicondutores usados para desempenhar as funçóes lógicas e de memória de alta velocidade e também os materiais magnéticos e ópticos utilizados para transmissão e comunicaçáo de informaçáo a longo prazo e baixo custo de armazenamento. Mas, acima de tudo, o campo está sofrendo um desvio: de produzir e vender chips semicondutores e outros componentes como produto final, passa a vender módulos funcionais. Tais módulos são usados em sistemas que têm impacto sobre toda nossa sociedade, economia e capacidade de defesa, tais como automóveis e aeroespaço, eletrônica para consumo e para defesa, automação de manufatura, sensoriamento e controle ambiental e a biblioteca do futuro. O desenvolvimento e a manufatura de módulos cada vez mais úteis coloca ênfase na contínua pesquisa voltada à miniaturização e nos obriga a considerar interconexốes e tecnologias modulares juntamente com desempenho e projetos integrados dos equipamentos. Assim, avanços nas tecnologias de informação estão relacionados a avanços em materiais semicondutores, fotônicos, magnéticos, fibras ópticas, isolantes, supercondutores, condutores, barreiras térmicas e empacotamento e em sua integração, interaçáo, manufatura e miniaturização.

A principal força de impacto social e penetração de mercado de circuitos integrados tem sido a contínua melhoria de projeto e processamento, permitindo que o número de dispositivos em um chip dobre a cada dois anos. Dobrar o número de dispositivos sem dobrar a área do chip requer tanto redução no tamanho dos dispositivos como da área ocupada pelas interconexóes. No passado, a diminuição da escala da geometria mínima dos dispositivos pavimentou o caminho da densidade funcional. Extrapolando, antecipa-se que a geometria mínima de circuitos integrados chegará a 0,25 micrômetros a partir de meados e até o final da década de 90 . Reduçóes maiores, usando os materiais hoje conhecidos, resultariam em degradação inaceitável a temperatura ambiente. A conclusão é que precisam ser desenvolvidos enfoques mais revolucionários em tecnologia de IC.

Maior miniaturização requer grande esforço de pesquisa de materiais para uso em dispositivos eletrônicos de circuito integrado, visando a superar os limites de escala, isto é, criando dispositivos pequenos e com elementos ativos e interconexóes mais densos. Para isso, novos princípios físicos seráo necessários, tanto em nível de projeto quanto de processamento. Além disso, deverão ser implementadas configuraçóes alternativas e fenômenos de transporte desses dispositivos.

Duas vias de pesquisa devem ser seguidas: as que retêm os materiais semicondutores, embora fazendo deles uso revolucionário; e enfo- 
ques não-semicondutores, tais como fotônica e supercondutividade. $O$ primeiro enfoque usa a experiência acumulada em manufatura e vai provavelmente migrar para processamento a baixas temperaturas, nos quais transiçóes químicas sáo controladas em nível atômico e onde heteroestruturas e novos fenômenos físicos podem ser invocados para superar as limitaçōes de escala das estruturas atuais. No final, a superação das limitaçóes de escala e o aumento de funcionalidade iráo exigir uma extensão da tecnologia, da presente, em duas dimensóes, para três dimensóes. O desenvolvimento de arquiteturas de microchip em 3-D apresenta enormes desafios e exigirá novas tecnologias de materiais, processos de manufatura mais sofisticados, novas estratégias para crescimento de materiais, novas arquiteturas para as interconexóes e novos enfoques quanto ao gerenciamento térmico. Além disso, conforme aumenta a funcionalidade do chip, aumentam também substancialmente as demandas sobre o empacotamento do sistema e suas interconexóes. $O$ empacotamento convencional e a tecnologia de interconexão estáo no limite. Para satisfazer à demanda por densidades mais elevadas nos chips, seráo necessárias novas tecnologias de empacotamento e interconexão e a integração destas com toda a tecnologia microeletrônica.

\section{Transportes}

\section{Aeronántica e aeroespacial}

Nos últimos $\mathbf{5 0}$ anos, os materiais usados em aeronáutica e aeroespacial têm sido os da variedade bi-tech, a exemplo das ligas de alumínio altamente resistentes, tais como a $7075 \mathrm{e}$ as ligas $\mathrm{Al}-\mathrm{Li}$, as ligas de Ti de alta temperatura, mais leves e fortes, as superligas de cristais únicos e novos compostos, tanto metálicos como poliméricos. A capacidade de antecipar, sintetizar, processar e manufaturar estruturas e motores para aeronáutica e aeroespacial, tanto militar como comercial, continua a exigir as mais imaginativas e requintadas aplicaçōes de física, metalurgia de processo e princípios sobre materiais. Por exemplo, o sofisticado casamento entre desenvolvimento de liga e modelagem de solidificaçáo levou a um novo tipo de tecnologia de fundiçăo e à manufatura e processamento bem-sucedidos de lâminas de turbina constituídas por superligas baseadas em níquel e formadas por grandes complexos de cristal único direcionalmente solidificados. Hoje, sáo esses os materiais preferidos nos sistemas de propulsão em todo o mundo.

Enfoques semelhantes seráo necessários para compreender, desenvolver e usar economicamente a nova geração de materiais, como os polímeros e os compósitos intermetálicos e cerâmicos. $O$ sucesso desses projetos-piloto multidisciplinares exigirá a integração bem-sucedida de 
novos projetos de motores, novas configurações de componentes estruturais e novas tecnologias de processamento e manufatura de materiais metálicos, intermetálicos cerâmicos e poliméricos que sejam operacionais a alta temperatura, resistentes e benignos para o meio-ambiente. Sucesso nessas áreas tecnológicas de base, se conseguido, pode ser prontamente estendido para o desenvolvimento de sistemas de ligas estruturais desta e de próxima geraçáo, que requerem operaçóes a altas temperaturas e estruturas muito mais leves, fortes e mais facilmente processáveis quando de sua produçăo.

\section{Indristria automotiva}

Acredita-se que as aplicaçóes nesse setor dependam largamente de materiais convencionais e, assim, não sujeitos a pesquisa e desenvolvimento sérios. Uma avaliação mais acurada mostra que o automóvel é um dos produtos mais complexos e sofisticados já desenvolvidos. Suas dez mil partes e componentes associados, sistemas e subsistemas fornecem o verdadeiro teste para automaçáo e produtividade. Além disso, pode servir de paradigma ideal para integrar os materiais já existentes e os avançados com processamento e manufatura de ponta, tudo dentro de limites de confiabilidade e custo aceitáveis. Talvez, a forma mais efetiva de ilustrar o tipo e magnitude dos problemas que hoje cercam os materiais usados na indústria automotiva seja catalogar os principais sistemas de materiais e as tendências tecnológicas genéricas. As descrições seguintes servem como indicadores dramáticos da amplitude das necessidades estruturais primárias em termos de materiais.

Os automóveis de hoje e do futuro serão feitos de folhas de aço, aços especializados, compósitos plásticos estruturais e năo-estruturais, elastômeros, tintas, metais não-ferrosos, peças moldadas, materiais de serviço e pintura e compósitos de matriz metálica. Além disso, serão partes do automóvel moderno materiais magnéticos, fibras ópticas, novos vidros e materiais sensitivos. Esses deverăo ser sintetizados e processados segundo altos padrōes e entáo integrados em projetos inovadores de processamento e manufatura. Essa tendência deverá dominar as agendas de pesquisa em projetos e desenvolvimento. Considerando os ganhos para o país e o desafio intelectual representado pela integraçáo de ciência dos materiais, engenharia e manufatura, $o$ ataque a esses problemas deve ser prioritário em qualquer agenda de pesquisa em materiais, ainda mais que o conhecimento adquirido poderá ser prontamente transferido para outros usuários de materiais estruturais.

\section{Materiais estruturais e outros sistemas de transporte}

A que novas oportunidades e benefícios econômicos podem levar 
os novos campos de processamento e manufatura de novos materiais? Exemplo muito citado é o dos supercondutores de alta temperatura, aplicáveis, talvez, a sistemas de transporte sobre trilhos, especialmente o Maglev. Sucesso exigirá o bom processamento não apenas de materiais de alta Tc, mas também dos materiais estruturais já existentes, seja para carros ou caminhóes, materiais sensitivos avançados etc. Outros exemplos de necessidade por materiais para infra-estrutura de transporte referem-se a cimento e materiais baseados em concreto, ligas metálicas resistentes a corrosão e a efetiva integração desses nas metodologias de construção. Todas essas aplicaçóes requerem persistência em buscar formas de prever as propriedades de materiais estruturais avançados.

\section{Energia}

\section{Energia e sociedade}

A energia desempenha papel singular nas sociedades do planeta. De um lado, é o sangue da vida econômica, que fornece os serviços e infra-estrutura essenciais para a civilizaçáo, tais como transporte, comunicações, alimento, produtos industriais e recreação. De outro, sua abundância ou carência determinam a segurança nacional, a competitividade industrial, o meio-ambiente, a economia e a estrutura social. Em 1989 , os EUA consumiram 81 quads $(81 \times 1015$ unidades térmicas britânicas) de energia. Isso equivale à energia que pode ser fornecida por 40 milhóes de barris de petróleo por dia em um ano. Significa um gasto de US $\$ 400$ bilhốes, sem considerar os custos de manutençáo da segurança do fornecimento. Algum fornecimento de energia é crucial para manter a segurança nacional.

O objetivo de uma estratégia energética nacional sólida é fornecer fontes de energia, conversão de energia e tecnologias de utilizaçăo que satisfaçam às necessidades nacionais de maneira economicamente eficiente e segura para o meio-ambiente. Náo existem fontes energéticas perfeitas. O petróleo tem disponibilidade limitada. Todos os combustíveis fósseis causam danos ambientais. As opçóes pela energia nuclear despertam preocupaçáo com segurança e destino de rejeitos. A energia solar é relativamente cara $\mathrm{e}, \mathrm{em}$ muitas áreas, pouco prática. E mesmo a conservaçăo exige larga participação social. $O$ desafio lançado à ciência é o de melhorar nossas técnicas de aproveitamento de energia e atingir conquistas que nos dêem novas opções.

\section{$A$ importancia para a energia da ciéncia}

e engenharia dos materiais

A ciência e engenharia de materiais têm um papel basilar em todo 
o ciclo de tecnologia energética, desde a melhoria das fontes primárias (petróleo, carvăo, gás natural, energia nuclear, hidrelétrica etc.), até novos sistemas para transmissão e conservaçáo e novos produtos e serviços para o consumidor. Melhorias evolutivas em materiais continuamente contribuem para aumentar a eficiência, confiabilidade e desempenho dos produtos finais; e o desenvolvimento de novos materiais e sistemas de materiais é necessário para novas opçóes de energia. A importância de ciência e engenharia de materiais pode ser melhor visualizada se considerarmos a demanda por novos materiais nas seguintes áreas relacionadas a energia: conversão e conservaçáo; opçóes nucleares; utilização elétrica; e opçóes futuras, tais como energia solar.

\section{Saúde}

O papel de materiais no campo da saúde depende das aplicaçóes. Essas incluem cuidado médico, produtos de suporte e destino de rejeitos médicos. Produtos volumosos e descartáveis dirigem a pesquisa para alternativas materiais economicamente competitivas e ecologicamente seguras. O desenvolvimento de novos materiais também é dirigido por produtos que possam aumentar e/ou manter a qualidade de vida ao mesmo tempo que reduzam o custo do atendimento médico, através da reduçáo de complicaçóes, redução da necessidade de revisóes e reduçáo do período de estadia hospitalar, mantendo ainda assim alto desempenho. Os gastos atuais com serviço de saúde, nos EUA, estáo na casa dos US\$ 600 bilhōes por ano (11\% do PIB), com projeção de US\$ 1,6 trilhóes (16\% do PIB) para o ano 2000. Esses custos incluem tratamento de rejeitos, bem como cuidado médico. É evidente que se deve continuar com os programas de pesquisa em materiais objetivando o campo da saúde.

\section{Meio-ambiente}

O meio-ambiente está emergindo como assunto crítico não apenas devido a seu impacto direto sobre a qualidade de vida, mas também por seu impacto nos processos e produtos industriais e meios de transporte. De fato, os aspectos ambientais da qualidade de vida, competitividade $e$ utilizaçáo de energia, incluindo transportes, beneficiar-se-iam de um esforço estratégico coordenado de $\mathrm{P} \& \mathrm{D}$, no qual $\mathrm{P} \& \mathrm{D}$ em materiais seria uma peça-chave.

O meio-ambiente coloca vários desafios que a comunidade de engenheiros e cientistas de materiais pode ajudar a resolver. Os desafios incluem limpeza, redução de lixo, armazenamento de tóxicos e melhor uso de produtos naturais. A comunidade que estuda materiais pode aju- 
dar a sociedade a alcançar um futuro no qual todos os produtos tenham ciclos de vida projetados de forma a haver um encadeamento de ciclos que náo produza lixo (por lixo, entenda-se produto secundário inuitil). As maneiras de se dar valor a energia e materiais seráo muito diferentes: cada produto será visto como ingrediente do produto posterior. Todo processo que produza produtos secundários intíteis ou de pouco valor será severamente desvalorizado. Para conseguir controle sobre o ciclo de vida dos materiais, será necessário: uso/reaproveitamento de materiais comerciais; projeto de novos materiais que possam ser indefinidamente reciclados; e processos para fazer novos materiais que náo impliquem rejeitos de produtos danosos para o meio-ambiente.

\title{
A INDÚSTRIA AERoESPACIAL: QUESTÓES ECONÔMICAS, TECNOLÓgICAS E SOCIAIS
}

\author{
GIORGIO E. O. GLACAGLIA \\ (Escola Politécnica da USP, São Paulo, Brasil)
}

\begin{abstract}
principal propósito desta palestra é o de analisar o papel que as atividades aeroespaciais tiveram e têm no desenvolvimento de uma sociedade melhor através da tecnologia. Nossa principal preocupação é nos concentrar na questão básica de quanto e onde uma nação deve investir em tecnologia, tecnologia aeroespacial em particular, e quais devem ser as bases para tais decisóes. A exploraçáo do espaço, como qualquer outra exploraçáo feita pela humanidade, deu à sociedade uma nova perspectiva de si própria e do Universo. Expandimos nosso conhecimento até as fronteiras do Sistema Solar e além delas. Quais são os benefícios dos investimentos feitos no sentido de atingir esses objetivos? Qual é o retorno mensurável? Quais os melhores investimentos que podemos imaginar para suprir nossas necessidades sociais e ampliar nossa compreensão acerca da própria vida?
\end{abstract}

